Provided for non-commercial research and education use. Not for reproduction, distribution or commercial use.

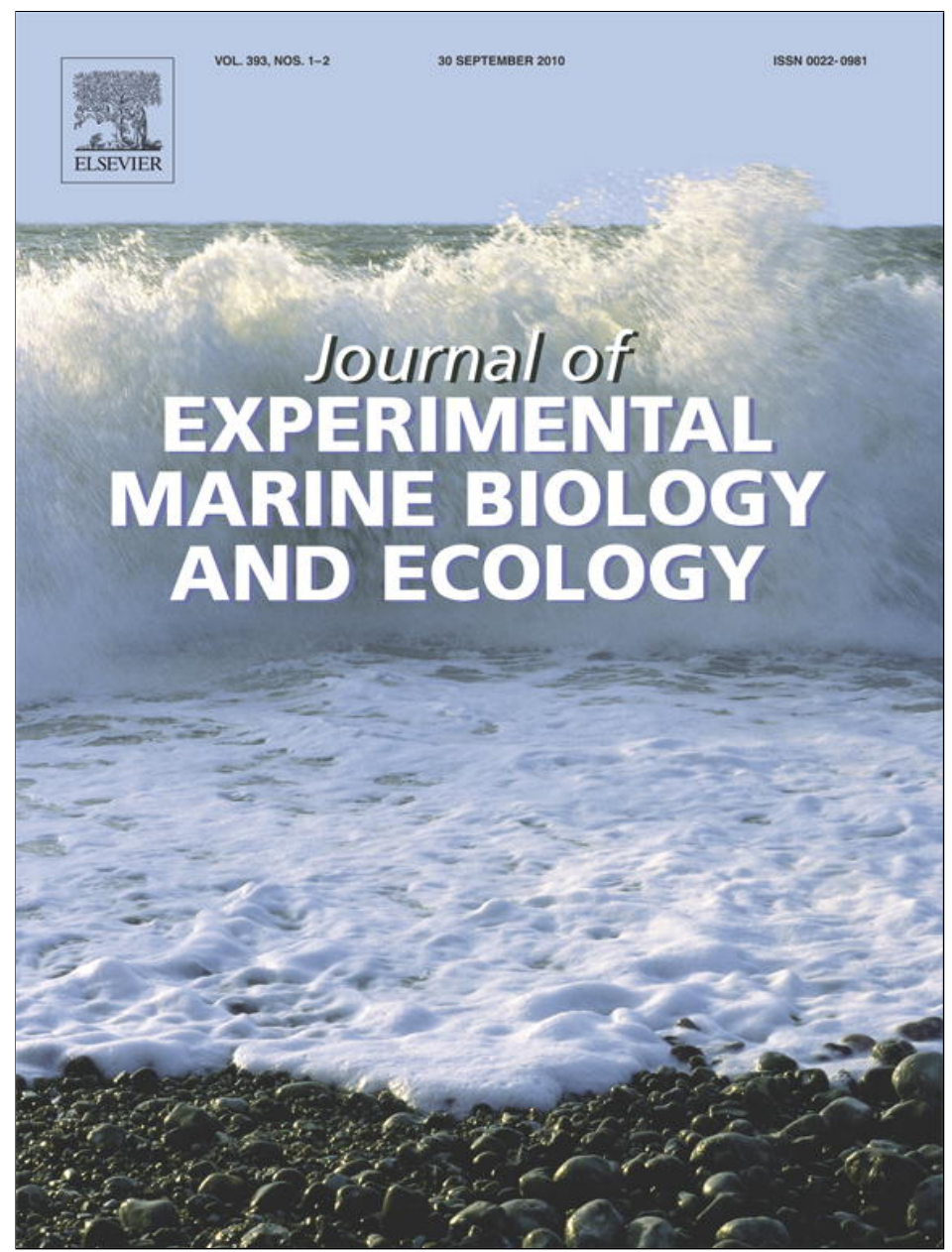

This article appeared in a journal published by Elsevier. The attached copy is furnished to the author for internal non-commercial research and education use, including for instruction at the authors institution and sharing with colleagues.

Other uses, including reproduction and distribution, or selling or licensing copies, or posting to personal, institutional or third party websites are prohibited.

In most cases authors are permitted to post their version of the article (e.g. in Word or Tex form) to their personal website or institutional repository. Authors requiring further information regarding Elsevier's archiving and manuscript policies are encouraged to visit:

http://www.elsevier.com/copyright 


\title{
Sediment preference and burrowing behaviour in the sympatric brittlestars Ophiura albida Forbes, 1839 and Ophiura ophiura (Linnaeus, 1758) (Ophiuroidea, Echinodermata)
}

\author{
Karin Boos ${ }^{\mathrm{a}, *}$, Lars Gutow $^{\mathrm{b}}$, Roger Mundry ${ }^{\mathrm{c}}$, Heinz-Dieter Franke ${ }^{\mathrm{a}}$ \\ a Biologische Anstalt Helgoland, Alfred Wegener Institute for Polar and Marine Research, PO Box 180, 27483 Helgoland, Germany \\ b Alfred Wegener Institute for Polar and Marine Research, PO Box 1201 61, 27515 Bremerhaven, Germany \\ c Max Planck Institute for Evolutionary Anthropology, Deutscher Platz 6, 04103 Leipzig, Germany
}

\section{A R T I C L E I N F O}

\section{Article history:}

Received 11 May 2010

Received in revised form 23 July 2010

Accepted 26 July 2010

\section{Keywords:}

Brittlestars

Burrowing

Feeding behaviour

Predation

Sediment preference

Coexistence

Niche segregation

\begin{abstract}
A B S T R A C T
Ophiura albida and Ophiura ophiura are widespread and highly abundant brittlestar species occurring sympatrically on soft bottoms along the western European coasts. Laboratory choice experiments revealed that 0 . albida preferred staying on fine rather than on coarse sediments, whereas O. ophiura did not distinguish between these types of sediment. Sediment-specific burrowing behaviour of the two species was investigated under different stress and food conditions in order to evaluate relations of predator avoidance and feeding strategies with the observed sediment preference. In the presence of a predator, O. albida burrowed preferentially in fine sediment while coarse sediment did not seem to support quick burrowing for efficient escape. Conversely, 0 . ophiura tended to escape the predator by fleeing across the sediment surface rather than by burrowing, reflecting its unselectivity towards different sediment types. For O. albida, stationary burrowing behaviour suggests deposit feeding, predating and/or scavenging on infaunal organisms to be the predominant feeding behaviour rather than hunting for epibenthic prey organisms; more so, as this foraging strategy reduces the species' exposure to predators. In contrast, 0 . ophiura seems to be a true hunter and predator for epibenthic prey which was reflected in the experiments by low burrowing activities in presence of food enriched sediments. We suggest that in 0 . albida and O. ophiura the evolution of different mechanisms of predator avoidance has been associated with the evolution of contrasting foraging strategies, supporting the species' coexistence in broadly overlapping habitats and explaining their distribution on different types of sediment in the German Bight (North Sea).
\end{abstract}

(C) 2010 Elsevier B.V. All rights reserved.

\section{Introduction}

Particle size and organic content have been the most commonly considered features for characterising sediment types and linking them to distributional patterns of a number of different taxa (Hagmeier, 1925; Stripp, 1969; Salzwedel et al., 1985; Quinn and Hickey, 1990; Bourassa and Morin, 1995; Rees et al., 1999; Freeman and Rogers, 2003). In ophiuroid echinoderms, studies on particle size selection and sediment preference have mainly focused on infaunal and cryptic species (Woodley, 1975; Clements and Stancyk, 1984; Sides and Woodley, 1985; Hendler and Littman, 1986), considering lifestyle, feeding mechanisms and protective strategies (Ursin, 1960; Buchanan, 1964; Warner, 1971; Tyler and Banner, 1977; Summers and Nybakken, 2000). Laboratory studies on the burrowing amphiurid brittlestar Microphiopholis gracillima, for example, showed that this species distinctly integrated both grain size and organic content into

* Corresponding author. Present address: Avitec Research GbR, Sachsenring 11, 27711 Osterholz-Scharmbeck, Germany. Tel.: +49 4795957 1531; fax: +49 47959574444

E-mail addresses: karin.boos@avitec-research.de, Karin.Boos@awi.de (K. Boos). its habitat choice as it is reflected in the species' distributional pattern observed in the field (Zimmerman et al., 1988).

While the burrowing lifestyle of infaunal brittlestars is considered an evolutionary adaptation to predator avoidance (Sköld, 1998), epibenthic brittlestars, for example from the genus Ophiura, have evolved other strategies to avoid predators, to temporarily hide from them or even to endure encounters. These include autotomy, rapid escape, deimatic behaviour and unwieldy shape, cryptic colouring and seeking shelter in crevices or under rocks (Fell, 1966; Hendler, 1984; Emson and Wilkie, 1980; Sköld and Rosenberg, 1996; Sköld, 1998). Although leading an epibenthic lifestyle, burrowing referring to a position just slightly below the sediment surface mostly with the arm tips still exposed above sediment level - has been reported to be a common response to potential stressors (e.g. predators or illumination) in Ophiura albida and Ophiura ophiura (Moore and Cobb, 1985; Sköld and Rosenberg, 1996; Sköld, 1998). MacGintie (1949) suggested that deposit feeding in 0 . sarsi may be related to burrowing behaviour which is likely to apply to other Ophiura species as well. Hereby the animals were observed dabbing their tube-feet over an organically enriched sediment surface and 
raking through the sediment with their arms followed by the subsequent burrowing of the entire body disc.

Experimental studies on sediment preference and burrowing behaviour in epibenthic brittlestars of the genus Ophiura are scarce. While Caspers (1979) reported that O. albida and O. ophiura selected distinctly different sediment types during early larval settlement, possible sediment preferences of adults so far could only be derived from observational monitoring studies and field sampling and have not revealed any clear patterns (Süßbach and Breckner, 1911; Gerdes, 1977; Salzwedel et al., 1985; Dahm, 1993; Kühne and Rachor, 1996; Niermann, 1997; Volbehr and Rachor, 1997; Boos and Franke, 2004).

O. albida and O. ophiura are common representatives of the boreolusitanian fauna distributed from Norway and Iceland to the Mediterranean and even as far as the Azores (Hyman, 1955; Ursin, 1960). Both species are considered omnivorous and have been reported to exhibit a wide range of feeding mechanisms including predation, scavenging as well as surface and sub-surface deposit feeding (Feder, 1981; Warner, 1982; Sköld and Rosenberg, 1996). In turn, they are predated upon by a number of demersal fishes such as haddock, plaice, dab and other flatfish and by various echinoderms and crustaceans making them important links in local food-webs and faunal communities (Fenchel, 1965; Warner, 1971; Pihl, 1994; Sköld, 1998; Summers and Nybakken, 2000). O. albida and O. ophiura are found sympatrically and in abundances of up to 700 ind. $\mathrm{m}^{-2}$ (Goldschmid, 1996) on a variety of different soft-bottom sediments in the southern North Sea including all grades of mud, gravel, sand and broken shell (Süßbach and Breckner, 1911; Salzwedel et al., 1985; Dahm, 1993; Kühne and Rachor, 1996; Niermann, 1997; Boos and Franke, 2004, 2006).

Common traits in 0 . albida and 0 . ophiura suggest that the two species have similar ecological requirements and are therefore likely to compete for shared resources. According to the classic 'competitive exclusion principle', however, two species cannot realize the same ecological niche (Hutchinson, 1957 in Soberón and Peterson, 2005; Hardin, 1960). The co-occurrence of O. albida and O. ophiura on softbottom sediments, therefore, indicates ecological differences between the two species that allow for their coexistence. While niche segregation among ecological equivalents is common in most communities (Ross, 1986), the mechanisms and factors allowing for the coexistence of species occupying the same habitat and utilizing the same resources, are often unknown.

In order to give a mechanistic explanation for the coexistence of 0 . albida and 0 . ophiura in the field, we studied possible sediment preferences of the species in the laboratory. Building on these results, we identified factors relating to sediment preferences. In detail we ask the following questions: Do 0 . albida and 0 . ophiura have different sediment preferences? If so, are the preferences related to burrowing behaviour performed as predator avoidance and/or feeding strategy? Can differences in these strategies explain for niche segregation and, thus, the coexistence of $O$. albida and 0 . ophiura?

To answer these questions, we applied single- and mixed-species sediment choice experiments with 0 . albida and 0 . ophiura at different densities in the laboratory. Subsequently, we investigated the burrowing behaviour of the two species on different sediment types under different stress and food conditions.

\section{Materials and methods}

\subsection{Sampling of animals and sediment treatment}

From June to July 2003, O. albida and 0 . ophiura were collected by dredging in the close vicinity of the island of Helgoland, German Bight (North Sea). Cultures of the two species of approximately 70 individuals each were maintained separately in $60 \times 45 \times 40 \mathrm{~cm}$ flow-through aquarium tanks at $16{ }^{\circ} \mathrm{C}$ and a light-dark cycle of
16:8 $\mathrm{h}$ in the seawater laboratory of the Helgoland Marine Station. Sediment was collected with a van Veen grab $\left(0.1 \mathrm{~m}^{2}\right)$ and offered as natural, untreated substratum. The ophiuroids were fed daily ad libitum with a mixed diet of commercial fish-food (TetraMin $\left.{ }^{\circledR}\right)$, tissue bits of blue mussels Mytilus edulis and small pieces of the isopod Idotea baltica. Leftover food particles were removed daily.

In all experiments only undamaged, i.e. non-regenerating adult individuals were used. All experiments were run at a constant temperature of $16{ }^{\circ} \mathrm{C}$. Sediment for experimental usage originated from van Veen grab samples taken along with the sediment sampled for maintenance purposes. Approximately $50 \mathrm{l}$ of sediment was dried and fractionated to different grain sizes by sieving through a cascade of sieves with decreasing mesh sizes $(3360,1800,1000,500,250$ and $125 \mu \mathrm{m})$. Subsequently, sediment fractions of two specific grain sizes were used throughout all experiments: $1000-1800 \mu \mathrm{m}$ and 125$250 \mu \mathrm{m}$. They will hereafter be referred to as coarse and fine sediment, respectively. Because this procedure is labour intensive and yields only relatively small quantities, the experimental sediments were used repeatedly. Prior to any experimental procedure, the sediments and basins were thoroughly washed with hot tap water in order to remove organic remains and chemical cues from animals of preceding experiments and to prevent microbial growth.

\subsection{Experimental setup}

\subsubsection{Sediment preference}

Either half of a round basin $(\varnothing=45 \mathrm{~cm}$, height $=15 \mathrm{~cm})$ was laid out with a 2-cm-thick layer of coarse and fine sediment, respectively, and then carefully filled up with seawater. Randomly chosen individuals of the respective species (mean disc diameter for O. albida: $7.4 \pm 0.7 \mathrm{~mm}$ and for 0 . ophiura: $12.7 \pm 1.3 \mathrm{~mm}$ ) were placed on the sediment, where the two sediment types bordered on each other. The numbers of individuals used in the experiments were chosen according to similar experiments by Sköld (1998). The maximum density of ophiuroids used in the present experiments was still low enough to allow for the animals' unimpeded migration in the basin throughout the experimental procedure (personal observation). The following numbers of individuals were used in single- and mixed-species trials; all trials were run with three replicates each:

- 5 individuals of 0 . albida and 0 . ophiura, respectively, in singlespecies treatments (for species-specific sediment preference)

- 10 individuals of 0 . albida and 0 . ophiura, respectively, in singlespecies treatments (for intraspecific or 'density' effects)

- 5 individuals of either species in mixed-species treatments (for interspecific or 'species' effects).

After a 2-h period of acclimatization to the artificial environment, the sediment choice of the ophiuroids was monitored constantly over a period of $8 \mathrm{~h}$. Ophiuroids are known to react negatively to light by seeking shelter under rocks, in crevices or by burrowing in sediments when illuminated (Fell, 1966; Moore and Cobb, 1985; Hendler, 2004). Moore and Cobb (1985) not only confirmed a negative phototaxis in 0 . ophiura but also showed distinct behavioural reactions in individuals that were exposed to different gradients of illumination. In order to prevent effects of directional photic stimuli on the animals' spatial distribution, the experiments were performed in the dark and were videotaped under infra-red light. Later the position of each individual at any given time was traced back on the screen. The moments in time of a sediment boundary crossing, i.e. when at least three legs of an individual had entirely crossed over to the respective other sediment type, were recorded for the entire trial duration. In this way, the total time spent on fine and coarse sediment was calculated for each individual. 


\subsection{Burrowing behaviour}

The burrowing behaviour of 0 . albida and 0 . ophiura on coarse and fine sediment was tested under different conditions of (i) a stressor and (ii) food. An ophiuroid was determined 'burrowed', as soon as its dorsal disc surface came equal with the sediment surface, independent of parts of the disc or the arms still being visible.

\subsubsection{Stress}

The burrowing behaviour in presence and absence (control) of a stressor, the edible crab Cancer pagurus, was studied using a round aerated basin $(\varnothing=45 \mathrm{~cm}$, height $=15 \mathrm{~cm})$ with a 2-cm-thick layer of coarse and fine sediment, respectively. C. pagurus was chosen as a predatory stressor as it is known to cause mechanical disturbance when browsing in dense epibenthic brittlestar populations (e.g. Ophiothrix fragilis) (Warner, 1971). We used medium sized C. pagurus with a mean carapax width of $8.4 \pm 1.2 \mathrm{~cm} .10$ conspecific ophiuroids (mean disc diameter for 0 . albida: $7.6 \pm 0.9 \mathrm{~mm}$ and for 0 . ophiura: $12.8 \pm 1.5 \mathrm{~mm}$ ) were transferred into the experimental basin and left for $2 \mathrm{~h}$ to acclimatize. After the acclimatization period, one individual of $C$. pagurus was introduced to the experiment. The number of burrowed ophiuroids was recorded every $5 \mathrm{~min}$ for a total period of $30 \mathrm{~min}$. Three replicates were run for each sediment type, treatment (control and trial) and ophiuroid species.

\subsubsection{Food}

The burrowing behaviour was studied in presence and absence (control) of food using $51(17 \times 15 \times 25 \mathrm{~cm})$ flow-through aquaria with a 2 -cm-thick layer of the respective sediment. In each set of food trials, the sediments in the aquaria were enriched by mixing them with $2 \mathrm{~g}$ of commercial fish food (TetraMin $\AA$ ), bits of tissue of 5 medium sized mussels ( $M$. edulis), approximately $15 \mathrm{~g}$ of isopod pieces (I. baltica) and freshly hatched nauplii of the brine shrimp Artemia salina, concentrated from 11 ( $3.5 \mathrm{ml}$ cysts/l seawater). After sedimentation of the food enriched sediment, food particles were available in the sediment as well as on the sediment surface meeting the requirements of the main feeding mechanisms in the genus Ophiura, i.e. epi- and endobenthic carnivory (scavenging and predation) and surface and subsurface deposit feeding.

In the experimental trials, three individuals of the same species (mean disc diameter for 0 . albida: $6.7 \pm 1.5 \mathrm{~mm}$ and for 0 . ophiura: $13.7 \pm 1.5 \mathrm{~mm}$ ), which had been starved for 2 days, were each transferred into a tank. After $2 \mathrm{~h}$ of acclimatization to the artificial environment, the number of burrowed individuals was recorded every $30 \mathrm{~min}$ for a total period of $8 \mathrm{~h}$. Five replicates with three individuals each were run for each sediment type, treatment (control and trial) and ophiuroid species.

\subsection{Statistical analysis}

All calculations were performed at the 95\% confidence level using computer software GraphPad Prism (3.0), STATISTIKA (7.1) or SPSS (15.0.0).

Ophiuroid sediment preference in single-species trials was analysed with a nested ANOVA with species and density as crossed fixed effects factors and experiment (with individuals as replicates) as random effects factor being nested in combinations of species and density. According to Zar (1999), we tested the two fixed effects factors and their interaction against the experiment mean square. In mixed-species comparisons, we used a crossed two-way ANOVA with species as fixed and experiment as random effects factor. Here we tested species against the interaction between the two factors and treatment as well as the interaction itself against the error mean square. In both analyses, we used the proportion of time spent on the coarse sediment as the response variable. Although Levene's test of homogeneity of error variances indicated clear deviations from this assumption (both $P<0.01$ ), we chose these analyses because inspections of plots of residuals against predicted values indicated no obvious deviations from normality and homogeneity of error variances (neither arcsin nor rank transformations improved fit to assumptions). To increase power and since no other factor than species nor any interaction revealed significance, we finally tested the data of both experiments pooled using a nested ANOVA with treatment as nested random effects factor and species as well as experimental condition (single vs. both species) as fixed effects factors. Both factors and their interaction were tested against the treatment mean square.

The burrowing behaviour of ophiuroids in both the stress and the food trials was analysed with repeated measures ANOVAs. Species (with levels: O. albida and O. ophiura) and sediment (with levels: coarse and fine) were treated as between subject factors having fixed effects, and experimental treatment (with levels: control and trial run) was included as a within subjects factor having fixed effects. Data +1 were log-transformed to meet the assumptions of normal distribution and homogeneous error variances (checked by visual inspection of the plot of the residuals against the predicted values and Levene's test: all except one $P>0.31$ ).

\section{Results}

\subsection{Sediment preference}

In the single-species treatments, the sediment choice of 0 . albida and 0 . ophiura tended to differ at low densities (nested ANOVA: $\left.F_{1,8}=4.99, P=0.056\right)$ but not at high densities $\left(F_{1,8}=0.09, P=0.77\right)$. However, the interaction between density and species was statistically not significant $\left(F_{1,8}=0.69, P=0.43 ;\right.$ Fig. 1$)$. In fact, $O$. albida tended to spend more time on fine sediment (mean $\pm S D=284.9 \pm 120.6 \mathrm{~min})$ than on coarse sediment (mean $\pm S D=195.0 \pm 120.7 \mathrm{~min}$ ), whereas 0 . ophiura did not do so $(222.4 \pm 210.8$ and $257.7 \pm 210.8 \mathrm{~min}$, respectively). In mixed-species experiments, we found no difference in sediment choice of the two species (ANOVA: $F_{1,2}=1.61, P=0.33$ ). Neither the treatment $\left(F_{1,2}=0.036, P=0.96\right)$ nor the interaction between treatment and species had a significant effect on the sediment choice of the two species $\left(F_{1,2}=0.43, P=0.66\right)$. Pooling all data sets of each species revealed that 0 . albida spent more time on the fine sediment than did 0 . ophiura $\left(F_{1,14}=6.44, P=0.024\right)$. The number of conspecifics and heterospecifics had no effect on sediment choice $\left(F_{1,14}=1.26, P=0.28\right)$ and the interaction between density and sediment was, again, not significant $\left(F_{1,14}=0.06, P=0.80\right)$.

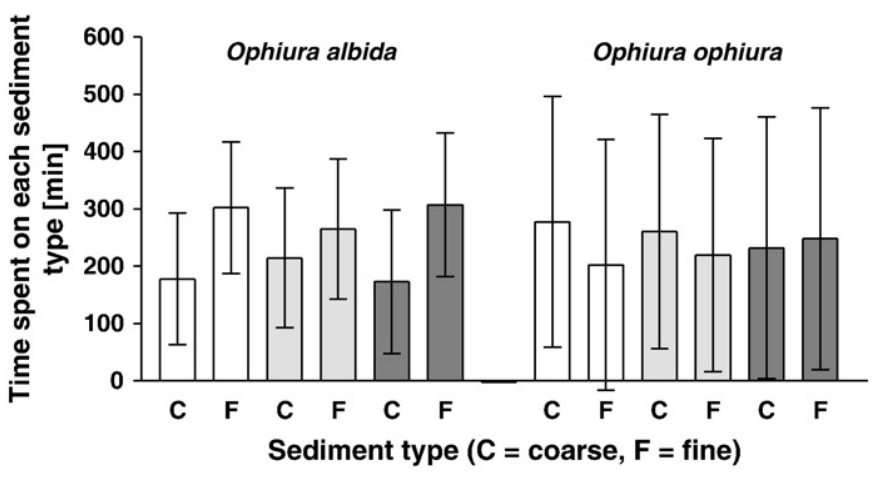

Fig. 1. Total time spent on coarse and fine sediment by Ophiura albida and Ophiura ophiura in different densities and species compositions; white bars $=$ single-species treatments ( 5 animals), light grey bars $=$ single-species treatments ( 10 animals $)$ and dark grey bars $=$ mixed-species treatments $(5+5$ animals $) ;$ mean $\pm \operatorname{SD}(N=15$ and 30 , respectively). 


\subsection{Burrowing behaviour}

\subsubsection{Stress}

The presence of the predator $C$. pagurus differentially influenced the burrowing behaviour of $O$. albida and $O$. ophiura on different sediment types (repeated measures ANOVA, species $\times$ condition $\times$ sediment type interaction: $F_{1,8}=6.32, P=0.04$; Fig. 2 ). 0 . albida showed higher burrowing activity in stress treatments than in stress-free conditions, whereas it was the opposite for 0 . ophiura. In both species, more animals were burrowed in fine than in coarse sediment $\left(F_{1,8}=6.08, P=0.04\right)$. Accordingly, the interaction between species and sediment was not significant $\left(F_{1,8}=0.20, P=0.67\right)$. 0 . albida generally showed higher burrowing activity than did 0 . ophiura $\left(F_{1,8}=7.90, P=0.023\right)$. Further interactions were not detected.

\subsubsection{Food}

Food availability in the sediment differentially influenced the burrowing behaviour of 0 . albida and 0 . ophiura (interaction species $\times$ feeding condition: $F_{1,16}=7.92, P=0.012$; Fig. 3 ). Burrowing activity of 0 . albida was enhanced in the presence of food whereas food enrichment of the sediment had no effect on the burrowing behaviour of $O$. ophiura. The two species also differed in their response to the sediment type (repeated measures ANOVA interaction, species $\times$ sediment: $F_{1,16}=13.92, P=0.002$ ). More individuals of 0 . albida were found burrowed in fine than in coarse sediment. The burrowing behaviour of 0 . ophiura was similar on both sediment types. Further interactions were not detected.

\section{Discussion}

When given a choice between the two sediment types, 0 . albida in all treatments, spent more time on fine sediment than on coarse sediment. The addition of conspecifics or heterospecifics did not alter this tendency making, intra- and interspecific effects on substrate selection negligible within the tested range of densities. O. ophiura, in contrast, showed no preference for any of the sediment types under study and was always found randomly distributed. It also did not respond to the addition of conspecifics or heterospecifics.
In both, the stress and the food trials, 0 . albida and O. ophiura generally showed higher burrowing activity on fine than on coarse sediment. On fine sediment, $O$. albida burrowed more often when the predator $C$. pagurus was present compared to when it was absent, while the opposite was found for 0 . ophiura. In the food trials, $O$. albida burrowed more often in fine sediment when it was enriched with food as when food was lacking. In contrast, $O$. ophiura generally remained on top of the sediment, independent of food enrichment.

Our results suggest that burrowing plays a greater role in the behavioural strategies (predator avoidance, foraging) of O. albida than in those of its congener 0 . ophiura. 0 . albida exhibited burrowing behaviour as a protective mechanism when encountering a potential predator. These findings are in accordance with earlier studies by Sköld (1998), where O. albida showed very little effort in fleeing, but remained still or covered itself slightly with sediment when exposed to a predator.

Burrowing in O. albida was observed more often on fine than on coarse sediment. Coarse sediments might present mechanical problems to burrowing (Stancyk, 1970 in Zimmerman et al., 1988; Woodley, 1967, 1975), thus not allowing for a quick escape in case of danger. Alternatively, being burrowed in coarse sediments may not provide an efficient protection from predators. Ehrenhauss et al. (2004) showed that due to enhanced water flow through larger pore sizes, transport rates of particles and dissolved chemical cues were higher in medium and coarse sands than in fine sands. Thus, burrowing as a protective mechanism against chemically orientated predators may be less efficient in coarse sediments as opposed to fine sediments. This effect may offer an explanation for the observed preference for fine sediments in O. albida.

In contrast to 0 . albida, 0 . ophiura does not seem to make use of burrowing as a protective mechanism against potential predators. In the present experiments 0 . ophiura tended to escape rapidly across the sediment surface on both fine and coarse sediment. This behaviour makes 0 . ophiura rather unselective towards sediment types as it does not seem to depend on a particular grain size to seek shelter from predators. These findings may explain for the lack of a clear preference in the sediment choice experiments.
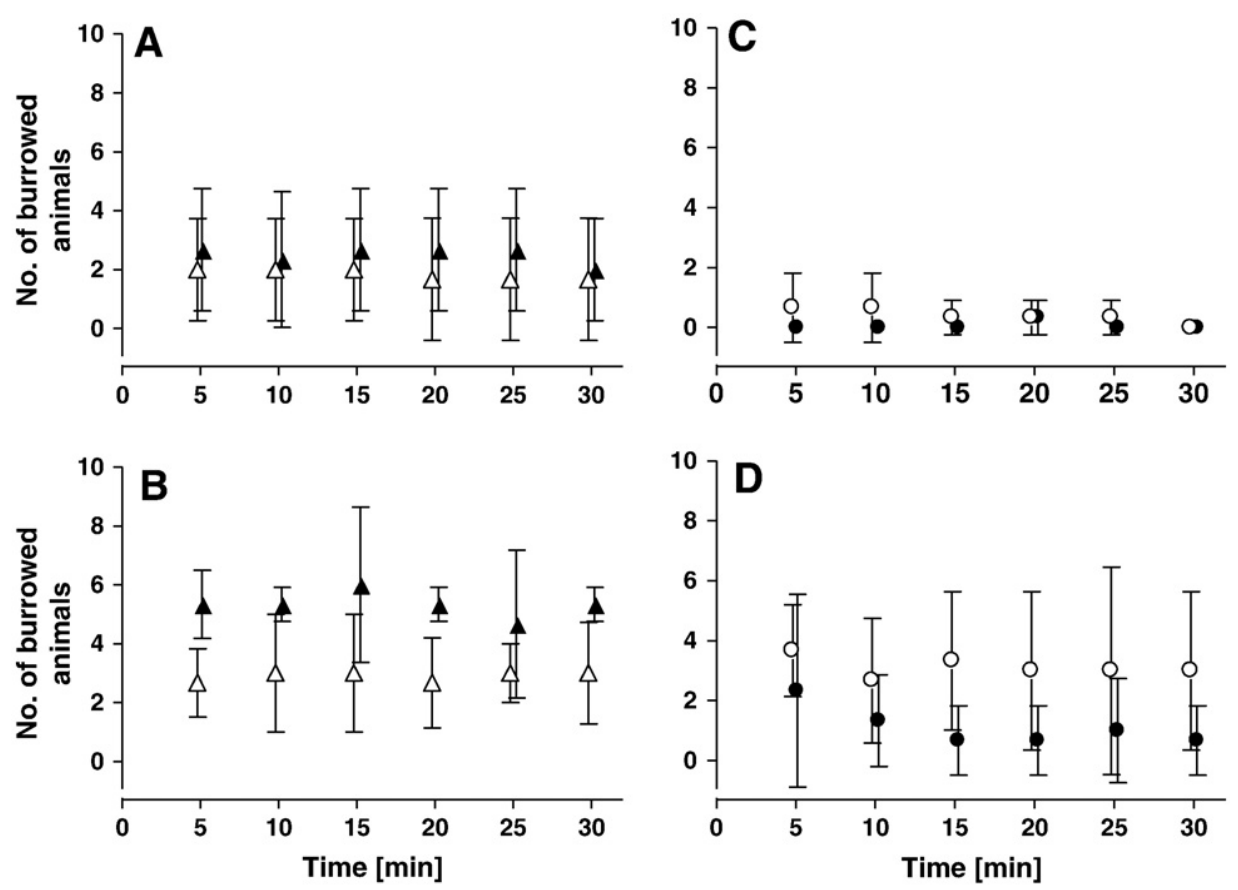

Fig. 2. Number of burrowed individuals of Ophiura albida $(\Delta \Delta)$ in coarse (A) and fine (B) and Ophiura ophiura ( $\bullet$ ) in coarse (C) and fine (D) sediment in presence (black symbols) and absence (white symbols) of predator stress over time; mean $\pm \operatorname{SD}(N=3)$. 

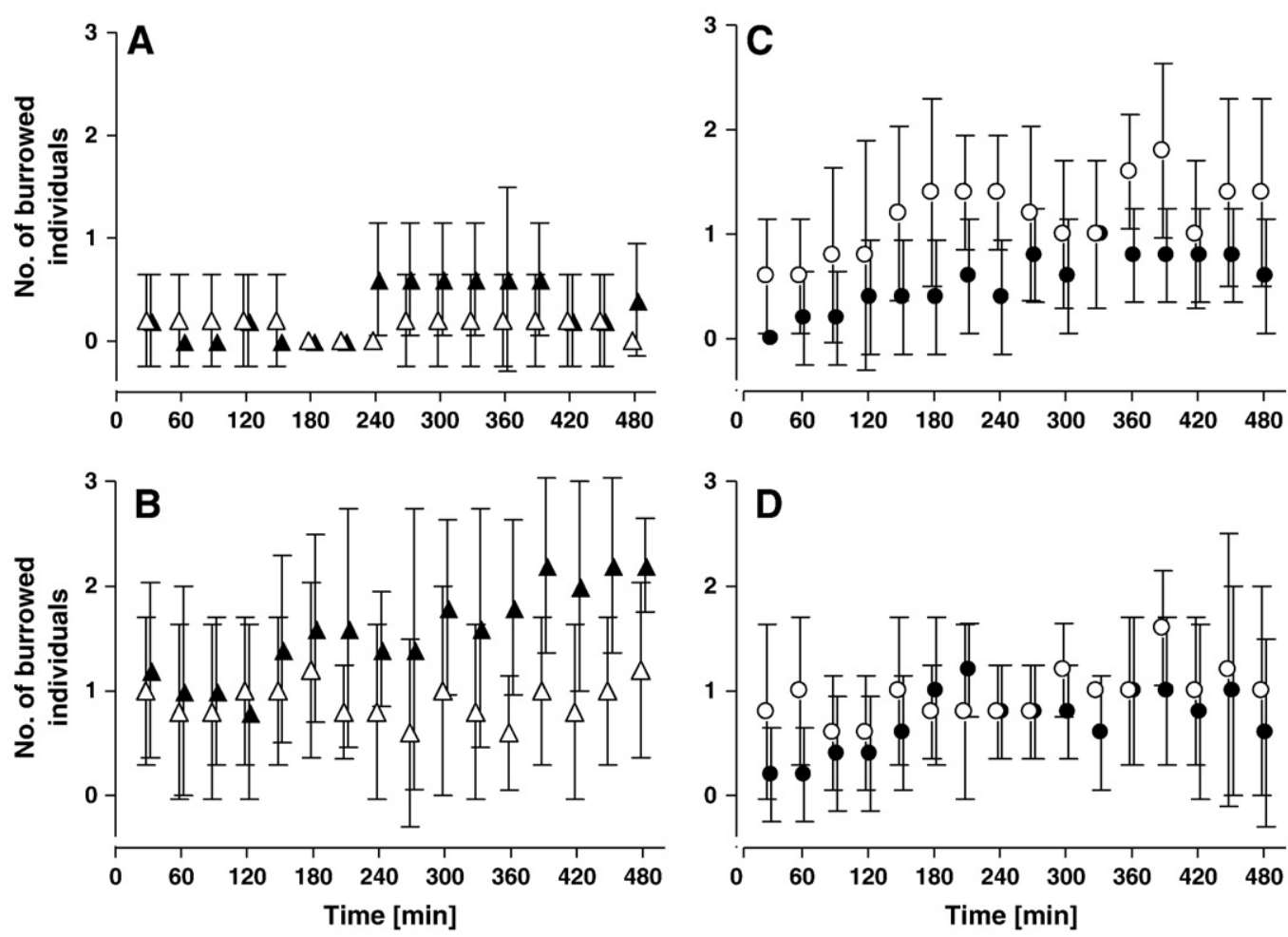

Fig. 3. Number of burrowed individuals of Ophiura albida $(\Delta \Delta)$ in coarse (A) and fine (B) sediment and Ophiura ophiura ( $)$ ) in coarse (C) and fine (D) sediment in presence (black symbols) and absence (white symbols) of food over time; mean \pm SD $(N=5)$.

The tendency in 0 . ophiura of rather digging itself out of the sediment and presenting itself when under threat is in accordance with the defence or escape mechanisms of epibenthic ophiuroids described by Sköld (1998). Horizontal locomotion in brittlestars typically takes place by using the entire arms instead of individual tube feet (Lawrence, 1987). By alternately moving two arms in the desired direction, the animals generally lift up their body over the surface dragging behind the other three arms (Lawrence, 1987). With a maximum disc diameter of approximately $30 \mathrm{~mm}$ and an arm length of four times the disc diameter (Mortensen, 1927), 0. ophiura is able to cover a larger distance much faster than 0 . albida, which is only about half the size of 0 . ophiura. This may explain the efficacy of a rapid escape in 0 . ophiura when under threat, whereas burrowing may be the better alternative for the smaller and slower moving 0 . albida. More so, as burrowing in slow moving species, like in most amphiurid ophiuroids, seems to be the predominant mechanism to seek shelter from predators such as demersal fishes (i.e. the dab Limanda limanda) or star fish (Fenchel, 1965; Summers and Nybakken, 2000; Saborowski and Buchholz, 1996). In addition, disc autotomy is also considered a very common mechanism of predator avoidance (Emson and Wilkie, 1980). With regard to autotomy, Stancyk (in Emson and Wilkie, 1980) suggested that not only does it enhance the chance of surviving predatory attacks, but, because of a smaller body size after autotomy, it may also allow for less resistance when burrowing in case of threat.

Being less active, slower and smaller than its congener, burrowing may make 0 . albida not only less prone to visually and/or chemically orientated predators. It may also reflect the species' stationary foraging behaviour, which includes subsurface deposit feeding as well as preying or scavenging on smaller infaunal organisms in the top layers of fine grained sediments, rather than hunting and actively searching for prey. Support is given by Eichelbaum (1910) and Jangoux and Lawrence (1982) who found comparably high amounts of sediment in stomach content analyses of $O$. albida in comparison to remains of small benthic organisms. Eichelbaum (1910) related more than $75 \%$ of ingested material to sediment ('bottom material') and designated 0 . albida as a deposit feeder. As fine grain sized sediments contain enhanced organic content and thus offer surface and subsurface deposit feeders substantial nutriment (Summers and Nybakken, 2000), they may also provide better feeding grounds for other infaunal organisms and potential prey objects, than do coarse grain sized sediments (Salzwedel et al., 1985). In turn, this may offer another explanation for the preference for fine sediment in O. albida observed in the present experiments.

Studying the stomach content and feeding behaviour of 0 . ophiura, Feder (1981) identified 41 prey organisms from different endo- and epibenthic taxa, including specimens of the congener 0 . albida. Because of the species' fairly unselective feeding behaviour (Tyler, 1977) and broad food spectrum, Feder (1981) designated O. ophiura as a predominant predator of small benthic organisms from a variety of different habitats, which, again, makes this species rather unspecific towards a certain sediment type.

Based on our results, we suggest that predator avoidance may play a primary role in explaining the differences between 0 . albida and 0 . ophiura with respect to substrate choice (preference for fine over coarse sediment in 0 . albida; no such preference in 0 . ophiura). The two species have evolved different strategies to escape or avoid potential predators and these differences are related to differences in the species' predominant foraging strategies. Differences in feeding habits, thus, may be considered the main factor allowing for the species' broad overlap in habitat use and coexistence observed in the field. In both species, increasing numbers of conspecifics as well as the presence of heterospecifics did not affect the outcome of sediment choice experiments within the small range of densities studied. While both species under study are known to perform a wide variety of predator avoidance strategies and feeding mechanisms, we were able to focus on some predominant behavioural responses to explain for an observed distribution of brittlestar populations in the German Bight (North Sea). Performances of additional feeding habits may play a role when looking into possible effects of competitive interactions on 
both, the intra- and interspecific level. These, however, have not been investigated in the present study.

\section{Acknowledgements}

The present study was carried out as part of a diploma thesis conducted at the Helgoland Marine Station, Alfred Wegener Institute for Polar and Marine Research, Germany (AWI). We gratefully acknowledge provision of research facilities and personnel support. Special thanks go to the captain and the crew of the MS "Uthörn" for their grand efforts throughout the sampling procedures. [SS]

\section{References}

Boos, K., Franke, H.-D, 2004 Abundance and distribution of ophiuroids off Helgoland, German Bight (North Sea). In: Heinzeller, T., Nebelsick, J. (Eds.), Echinoderms: München. A.A. Balkema Publishers, Leiden, pp. 157-158.

Boos, K., Franke, H.-D., 2006. Brittle stars (Echinodermata: Ophiuroidea) in the German Bight (North Sea)-species diversity during the past 130 years. J. Mar. Biol. Assoc. U.K. 86, 1187-1197.

Bourassa, N., Morin, A., 1995. Relationships between size structure of invertebrate assemblages and trophy and substrate composition in streams. J. N. Am. Benthol. Soc. $14,393-403$.

Buchanan, J.B., 1964. A comparative study of some features of the biology of Amphiura filiformis and Amphiura chiajei (Ophiuroidea) considered in relation to their distribution. J. Mar. Biol. Assoc. U. K. 44, 565-576.

Caspers, H., 1979. Adaptation and biocoenotic associations of echinoderms in a sewage sludge dumping area of the southern North Sea. A macroscale experiment. Proceedings of the European Colloquium on Echinoderms, Brussels, pp. 189-198.

Clements, L.A.J., Stancyk, S.E., 1984. Particle selection by the burrowing brittlestar Microphiopholis gracillima (Stimpson) (Echinodermata: Ophiuroidea). J. Exp. Mar. Biol. Ecol. 84, 1-13.

Dahm, C., 1993. Growth, production and ecological significance of Ophiura albida and O. ophiura (Echinodermata: Ophiuroidea) in the German Bight. Mar. Biol. 116, 431-437.

Ehrenhauss, S., Witte, U., Bühring, S.I., Huettel, M., 2004. Effect of advective pore water transport on distribution and degradation of diatoms in permeable North Sea sediments. Mar. Ecol. Prog. Ser. 271, 99-111.

Eichelbaum, E., 1910. Über Nahrung und Ernährungsorgane von Echinodermen. Wiss. Meeresunters. Kiel 11, 187-274.

Emson, R.H., Wilkie, I.C., 1980. Fission and autotomy in echinoderms. Oceanogr. Mar. Biol. Ann. Rev. 18, 155-250.

Feder, H.M., 1981. Aspects of the feeding biology of the brittlestar Ophiura texturata. Ophelia 20, 215-235.

Fell, H.B., 1966. The ecology of ophiuroids. In: Boolootian, R.A. (Ed.), Physiology of Echinodermata. Interscience Publishers, New York, pp. 129-143.

Fenchel, T., 1965. Feeding biology of the sea-star Luidia sarsi Düben \& Koren. Ophelia 2, 223-236.

Freeman, S.M., Rogers, S.I., 2003. A new analytical approach to the characterisation of macro-epibenthic habitats: linking species to the environment. Estuar. Coast. Shelf Sci. 56, 749-764.

Gerdes, D., 1977. Zur Verteilung der Echinodermen in der Deutschen Bucht. Diploma thesis, Institut für Meereskunde, Kiel.

Goldschmid, A., 1996. Echinodermata, Stachelhäuter. In: Westheide, W., Rieger, R. (Eds.), Spezielle Zoologie, Teil 1: Einzeller und Wirbellose Tiere. Gustav Fischer Verlag, Stuttgart, pp. 778-834.

Hagmeier, A., 1925. Vorläufiger Bericht über die vorbereitenden Untersuchungen der Bodenfauna der Deutschen Bucht mit dem Petersen-Bodengreifer. Ber. Dtsch. Wiss. Komm. N.F. 1, 247-272.

Hardin, G., 1960. The competitive exclusion principle. Science 131, 1292-1297.

Hendler, G., 1984. Brittlestar color-change and phototaxis (Echinodermata: Ophiuroidea: Ophoicomidae). PSZN I: Mar. Ecol. 5, 379-401.

Hendler, G., 2004. An echinoderm's eye view of photoreception and vision. In: Heinzeller, T., Nebelsick, J. (Eds.), Echinoderms: München. A.A. Balkema Publishers, Leiden, pp. 339-349.

Hendler, G., Littman, B.S., 1986. The ploys of sex: relationships among the modes of reproduction, body size and habitats of coral-reef brittlestars. Coral Reefs 5, 31-42.
Hutchinson, G.E., 1957. Concluding Remarks. Cold Spring Harbor Symp. Quant. Biol. 22, 415-442.

Hyman, L.H., 1955. The Invertebrates: Echinodermata. McGraw-Hill Book Company Inc., New York.

Jangoux, M., Lawrence, J.M. (Eds.), 1982. Echinoderm Nutrition. A.A. Balkema, Rotterdam.

Kühne, S., Rachor, E., 1996. The macrofauna of a stony sand area in the German Bight (North Sea). Helgol. Meeresunters. 50, 433-452.

Lawrence, J., 1987. A functional biology of echinoderms. Croom Helm, London, p. 340.

MacGintie, G.E., 1949. The feeding of ophiurans. J. Ent. Zool. 41, 27-29.

Moore, A., Cobb, J.L.S., 1985. Neurophysiological studies on photic responses in Ophiura ophiura. Comp. Biochem. Physiol. 80A, 11-16.

Mortensen, T., 1927. Handbook of the echinoderms of the British Isles. Humphrey Milford-Oxford University Press, Oxford.

Niermann, U., 1997. Macrobenthos of the south-eastern North Sea during 1984-88. Ber. Biol. Anst. Helgoland 13, 1-144.

Pihl, L., 1994. Changs in the diet of demersal fish due to eutrophication-induced hypoxia in the Kattegat, Sweden. Can. J. Fish. Aquat. Sci. 51, 321-336.

Quinn, J.M., Hickey, C.W., 1990. Magnitude of effects of substrate particle size, recent flooding, and catchment development on benthic invertebrates in 88 New Zealand rivers. N.Z. J. Mar. Freshwater Res. 24, 411-427.

Rees, H.L., Pendle, M.A., Waldock, R., Limpenny, D.S., Boyd, E.S., 1999. A comparison of benthic biodiversity in the North Sea, English Channel, and Celtic Seas. ICES J. Mar. Sci. 56, 228-246.

Ross, S.T., 1986. Resource partitioning in fish assemblages: a review of field studies. Copeia 2, 352-388.

Saborowski, R., Buchholz, F., 1996. Annual changes in the nutritive state of North Sea dab. J. Fish Biol. 49, 173-194.

Salzwedel, H., Rachor, E., Gerdes, D., 1985. Benthic macrofauna communities in the German Bight. Veröff. Inst. Meeresforsch. Bremerh. 20, 199-267.

Sides, E.M., Woodley, J.D., 1985. Niche separation in three species of Ophiocoma (Echinodermata: Ophiuroidea) in Jamaica, West Indies. Bull. Mar. Sci. 36, $701-715$.

Sköld, M., 1998. Escape responses in four epibenthic brittlestars (Ophiuroidea: Echinodermata). Ophelia 49, 163-179.

Sköld, M., Rosenberg, R., 1996. Arm regeneration frequency in eight species of ophiuroidea (Echinodermata) from European Sea areas. J. Sea Res. 35, 353-362.

Soberón, J., Peterson, A.T., 2005. Interpretation of models of fundamental and ecological niches and species' distribution areas. Biodivers. Inform. 2, 1-10.

Stripp, K., 1969. Die Assoziationen des Benthos der Helgoländer Bucht. Veröff. Inst. Meeresforsch. Bremerh. 12, 95-141.

Summers, A.C., Nybakken, J., 2000. Brittle star distribution and population densities on the continental slope off central California (Echinodermata: Ophiuroidea). Deep Sea Res. Part II 47, 1107-1137.

Süßbach, S., Breckner, A., 1911. Die Seeigel, Seesterne und Schlangensterne der Nordund Ostsee. Wiss. Meeresunters. 12, 169-300

Tyler, P.A., 1977. Seasonal variation and ecology of gametogenesis in the genus Ophiura (Ophiuroidea: Echinodermata) from the Bristol Channel. J. Exp. Mar. Biol. Ecol. 30, 185-197.

Tyler, P.A., Banner, F.T., 1977. The effect of coastal hydrodynamics on the echinoderm distribution in the sublittoral of Oxwich Bay, Bristol Channel. Estuar. Coast. Mar. Sci. $5,293-308$.

Ursin, E., 1960. A quantitative investigation of the echinoderm fauna of the central North Sea. Meddelelser Fra Danmarks Fiskeri- Og Havundersøgelser 2, 1-204.

Volbehr, U., Rachor, E., 1997. The association between the caprellid Pariambus typicus Krøyer (Crustacea, Amphipoda) and ophiuroids. Hydrobiologia 355, 71-76.

Warner, G.F., 1971. On the ecology of a dense bed of the brittle-star Ophiothrix fragilis. J. Mar. Biol. Assoc. U. K. 51, 267-282.

Warner, G.F., 1982. Food and feeding mechanisms: Ophiuroidea. In: Jangoux, M., Lawrence, J.M. (Eds.), Echinoderm nutrition. A.A. Balkema, Rotterdam, pp. 161-181

Woodley, J.D., 1967. Problems in the ophiuroid water-vascular system. In: Millot, N. (Ed.), Echinoderm biology. : Symp. Zool. Soc. London, No. 20. Academic Press, London, pp. 75-104.

Woodley, J.D., 1975. The behavior of some amphiurid brittlestars. J. Exp. Mar. Biol. Ecol. $18,29-46$.

Zar, J.H., 1999. Biostatistical Analysis, 4th ed. Prentice Hall, New Jersey.

Zimmerman, K.M. Stancyk, S.E., Clements, L.A.J., 1988. Substrate selection by the burrowing brittlestar Microphiopholis gracillima (Stimpson) (Echinodermata: Ophiuroidea). Mar. Behav. Physiol. 13, 239-255. 